\title{
Cross-sectional associations between genetic polymorphisms in metabolic enzymes and longer leukocyte telomere length induced by omethoate
}

\author{
Xiaoran Duan ${ }^{1}$, Yongli Yang${ }^{2}$, Sihua Wang ${ }^{3}$, Xiaolei Feng ${ }^{1}$, Tuanwei Wang ${ }^{1}$, \\ Pengpeng Wang ${ }^{1}$, Suxiang Liu ${ }^{4}$, Lei $\mathrm{Li}^{4}$, Guoyu $\mathrm{Li}^{4}$, Wu Yao ${ }^{1}$, Liuxin Cui ${ }^{1}$ and Wei \\ Wang $^{1}$ \\ ${ }^{1}$ Department of Occupational and Environmental Health, College of Public Health, Zhengzhou University, Zhengzhou, China \\ ${ }^{2}$ Department of Epidemiology and Biostatistics, College of Public Health, Zhengzhou University, Zhengzhou, China \\ ${ }^{3}$ Department of Occupational Health, Henan Institute for Occupational Medicine, Zhengzhou, China \\ ${ }^{4}$ Clinical Department, Zhengzhou Institute of Occupational Health, Zhengzhou, China \\ Correspondence to: Wei Wang, email: ww375@126.com \\ Yongli Yang, email: ylyang377@126.com
}

Keywords: omethoate, telomere, polymorphism, metabolic enzymes

Received: June 27, 2017 Accepted: August 29, $2017 \quad$ Published: September 18, 2017

Copyright: Duan et al. This is an open-access article distributed under the terms of the Creative Commons Attribution License 3.0 (CC BY 3.0), which permits unrestricted use, distribution, and reproduction in any medium, provided the original author and source are credited.

\section{ABSTRACT}

Purpose: This study aimed to explore the effects of genetic polymorphisms in metabolic enzymes on relative telomere length changes and explore the mechanism of canceration induced by omethoate.

Materials and Methods: 180 long-term omethoate-exposed workers and 115 healthy controls were recruited. Real-time PCR method was applied to determine the relative telomere length in peripheral blood leukocytes DNA, and Six polymorphic loci of GSTT1(+/-), GSTM1(+/-), GSTP1 rs1695, CYP2E1 rs6413432, CYP2E1 rs3813867 and PON2 rs12026 were detected by polymerase chain reaction and restriction fragment length polymorphism method; Multiple linear regression was conducted to explore the effects of omethoate exposure and genetic polymorphisms on the telomere length.

Results: The relative telomere lengths in the control group $(0.94[0.76,1.32])$ were significantly shorter than that in the exposure group (1.50 [1.11, 2.57]) $(Z=7.910, P<0.001)$. Univariate analysis showed that the relative telomere lengths of the GSTM1-deletion individuals were significantly longer than that of the non - deletion genotype in the control group $(Z=2.911, P=0.004)$, and the relative telomere lengths of GSTP1 rs1695 polymorphism locus (GG+AG) genotype individuals were longer than that of AA genotype in the exposure group. The difference was statistically significant $(Z=2.262, P=0.024)$. Multivariate analysis found that pesticide-exposure $(b=0.524, P<0.001)$ and GSTM1 polymorphism $(b=-0.136$, $P=0.029$ ) had an impact on telomere length.

Conclusions: The relative telomere lengths of omethoate-exposure workers were longer than that in the control population. Also GSTM1 genetic polymorphism may influence the changes of the telomere length induced by omethoate.

\section{INTRODUCTION}

Omethoate is an organophosphorous insecticide and acaricide that is highly toxic, highly effective and broadspectrum features. In the process of its use and production, it can cause certain harm to the health of persons who come into contact with it, such as chronic toxicity caused by longterm, low-dose exposure which is easy to be ignored $[1,2]$. In recent years, acute organophosphorous poisoning incidents have been gradually reduced, and people are 
more concerned about the chronic toxic effect caused by long-term, low-dose exposure to OPs. More and more studies have concluded that there was a close relationship between long-term, low-dose exposure Ops and many human diseases, such as tumorigenesis, adverse reproductive outcomes, and neurological and neurobehavioral function abnormalities [3-5]. Studies on organophosphorous pesticides involving genetic damage mainly included comet assay, micronucles (MN), and sister chromatid exchange (SCE) [6-11]. However, it was rarely reported that OPs induced telomere damage. Telomere is specialized DNA-protein functional complex which is located at the end of the chromosome and is more susceptible to be attacked by exogenous compounds, telomere excessive consumption or structural disruption can result in cell carcinogenesis [12]. Therefore, telomere length can be used as an effect marker for analysis and research.

Organophosphorous pesticides experience a complex metabolic process after entering into the body. A wide variety of enzymes are involved in the organophosphorus metabolism, including the active enzyme in the phase I reaction and the binding enzyme in the phase II reaction. The activity of enzymes and the metabolic level are different for each person; therefore, not all individuals will produce genetic damage under the same contact conditions, suggesting that genetic susceptibility is different for individuals who are exposed to an organophosphorus pesticide. At present, much attention has been given to the five functional genes GSTM1, GSTT1, GSTP1, CYP2E1, and PON2 polymorphisms. Enzymes encoded by these genes are involved in metabolism and detoxification of exogenous substances. Studies have shown that the GSTM1 null genotype could increase the tail moment of the comet assay in workers occupationally exposed to OPs [13]. A previous study performed in pesticide-exposed fruit growers also showed that the mutant genotype of GSTP1 rs1695 polymorphism locus was associated with an increased risk of DNA damage measured by the comet assay [14]. Wong et al [15] researched the relationship between XRCC1, $C Y P 2 E 1$ and $A L D H 2$ genetic polymorphisms and the sister chromatid exchange (SCE) frequency and found that CYP2E1 rs3813867 mutant genotype CC could increase SCE frequency. Paraoxonase 2 (PON2) is a member of the paraoxonase gene family which can protect cells from oxidative stress and thus protect chromosomes from damage. Variants of rs12026 within the PON2 gene were associated with cardiovascular disease, cerebrovascular disease, diabetes and other diseases [16, 17]. However, the relationship between these genetic polymorphisms and telomere length in workers exposed to omethoate has not been reported.

Therefore, we studied telomere length changes in workers exposed to omethoate and the effects of the above five metabolism genetic polymorphisms.

\section{RESULTS}

\section{Demographic characteristics of the study population}

Table 1 showed the compared results of gender, age, smoking and drinking history between the two groups. Gender, age, smoking and drinking history had significant differences between the two groups. We regarded 40 years old as the boundary and divided the ages into the low and high age group according to the segments of Chinese age.

\section{The detecting results of external exposure}

According to the detecting reports from 2011 to 2013, the $8 \mathrm{~h}$ time-weighted average and short-term exposure concentrations were lower than occupational exposure limits prescribed by the state in each type of work.

\section{The determination results of relative telomere length}

Statistical analysis found that the relative telomere lengths in the normal controls $(0.94[0.76,1.32])$ were significantly shorter than that of the exposed group (1.50 $[1.11,2.57])(\mathrm{Z}=7.910, P<0.001)$.

\section{Effects of gender, age, smoking, drinking and working duration on telomere length}

To analyze the correlation between age and telomere length using the Spearman rank correlation, we found that there was no correlation in the exposure or control group, respectively $\left(r_{s}=0.049, P=0.517 ; r_{s}=0.116, P=0.218\right)$. Table 2 showed that gender, age, smoking, drinking and working duration had no effect on the relative telomere length in the exposure or control $\operatorname{group}(P>0.05)$. However, the relative telomere lengths were different between the two groups in the same stratification, and the difference were statistically significant $(P<0.05)$.

\section{Effects of genetic polymorphisms on telomere lengths}

The genotype distribution in these loci conformed to the Hardy-Weinberg balance $(P>0.05)$, suggesting the control samples had representativeness. To regard wild homozygous genotype as a reference, we analyzed the differences of relative telomere length between heterozygous or mutant homozygous genotype and wild homozygous genotype. Among them, the wild homozygous genotype of GSTP1rs1695 locus and mutation homozygous genotype of PON2 rs12026 locus were 2 cases and 3 cases respectively in the exposure group; therefore, they would be a merger with the 
Table 1: General characteristics of exposure and control groups (\%)

\begin{tabular}{lccccc}
\hline \multicolumn{1}{c}{ Variable } & Exposure & Control & Total & $\chi^{\mathbf{2}}$ & $\boldsymbol{P}$ \\
\hline Gender & & & & & \\
$\quad$ Male & $137(76.1)$ & $54(47.0)$ & $191(64.7)$ & 26.130 & $<0.001$ \\
$\quad$ Female & $43(23.9)$ & $61(53.0)$ & $104(35.3)$ & & \\
Age(years) & & & & \\
$\quad \leq 40$ & $53(29.4)$ & $67(58.3)$ & $120(40.7)$ & 24.146 & $<0.001$ \\
$\quad>40$ & $127(70.6)$ & $48(41.7)$ & $175(59.3)$ & & \\
Smoking & $63(35.0)$ & $12(10.4)$ & $75(25.4)$ & 22.333 & $<0.001$ \\
$\quad$ Yes & $117(65.0)$ & $103(89.6)$ & $220(74.6)$ & & \\
$\quad$ No & $16(8.9)$ & $30(26.1)$ & $46(15.6)$ & 15.769 & $<0.001$ \\
Drinking & $164(91.1)$ & $85(73.9)$ & $249(84.4)$ & & \\
$\quad$ Yes & & & & \\
$\quad$ No & & & & \\
\hline
\end{tabular}

Table 2: The effects of sex, age, smoking, drinking and working duration on telomere length

\begin{tabular}{|c|c|c|c|c|c|c|}
\hline \multirow{2}{*}{ Variables } & \multicolumn{2}{|c|}{ Exposure } & \multicolumn{2}{|r|}{ Control } & \multirow{2}{*}{$Z^{*}$} & \multirow{2}{*}{$P^{*}$} \\
\hline & $n$ & $M\left(P_{25}, P_{75}\right)$ & $n$ & $M\left(P_{25}, P_{75}\right)$ & & \\
\hline \multicolumn{7}{|l|}{ Gender } \\
\hline Male & 137 & $1.50(1.10,2.57)$ & 54 & $0.93(0.77,1.16)$ & 6.871 & $<0.001$ \\
\hline Female & 43 & $1.79(1.11,2.90)$ & 61 & $1.08(0.74,1.48)$ & 4.360 & $<0.001$ \\
\hline $\mathrm{Z}^{\#}$ & & 0.787 & & 1.569 & & \\
\hline$P^{\#}$ & & 0.431 & & 0.117 & & \\
\hline \multicolumn{7}{|l|}{ Age } \\
\hline$\leq 40$ & 53 & $1.50(1.26,2.44)$ & 67 & $0.95(0.77,1.32)$ & 5.356 & $<0.001$ \\
\hline$>40$ & 127 & $1.54(1.06,2.62)$ & 48 & $0.94(0.73,1.34)$ & 5.568 & $<0.001$ \\
\hline $\mathrm{Z}^{\#}$ & & -0.328 & & -0.556 & & \\
\hline$P^{\#}$ & & 0.743 & & 0.578 & & \\
\hline \multicolumn{7}{|l|}{ Smoking } \\
\hline Yes & 63 & $1.50(1.08,2.48)$ & 12 & $1.20(0.94,1.33)$ & 2.298 & 0.022 \\
\hline No & 117 & $1.54(1.13,2.66)$ & 103 & $0.94(0.74,1.32)$ & 7.254 & $<0.001$ \\
\hline$Z \#$ & & -0.321 & & -1.409 & & \\
\hline$P^{\#}$ & & 0.748 & & 0.159 & & \\
\hline \multicolumn{7}{|l|}{ Drinking } \\
\hline Yes & 16 & $1.50(1.20,2.22)$ & 30 & $0.92(0.76,1.28)$ & 3.759 & $<0.001$ \\
\hline No & 164 & $1.50(1.10,2.61)$ & 85 & $0.95(0.76,1.35)$ & 6.753 & $<0.001$ \\
\hline$Z^{\#}$ & & -0.065 & & -0.293 & & \\
\hline$P^{\#}$ & & 0.948 & & 0.770 & & \\
\hline \multicolumn{7}{|l|}{ Working duration } \\
\hline$<15$ & 26 & $1.61(1.23,2.70)$ & & & & \\
\hline $15 \sim 30$ & 117 & $1.54(1.12,2.72)$ & & & & \\
\hline$>30$ & 37 & $1.35(0.99,2.20)$ & & & & \\
\hline$\chi 2^{\#}$ & & 2.251 & & & & \\
\hline$P^{\#}$ & & 0.324 & & & & \\
\hline
\end{tabular}

Note: $P^{*}$ indicates the comparison of telomere length between exposure group and control group after stratifying, $P^{\sharp}$ represents the comparison among the layers after stratifying.

heterozygous genotype directly. The relationships between genetic polymorphisms and telomere lengths are shown in Table 3. The results show that the relative telomere length of the GSTM1 polymorphism deletion genotype was significantly longer than that of the non-deletion genotype in the control group $(Z=2.911, P=0.004)$, and the relative 
Table 3: The relationships between genetic polymorphism and telomere lengths

\begin{tabular}{|c|c|c|c|c|c|c|c|c|}
\hline \multirow{2}{*}{ SNPs } & \multicolumn{4}{|c|}{ Exposure } & \multicolumn{4}{|c|}{ Control } \\
\hline & $n$ & $M\left(P_{25}, P_{75}\right)$ & $Z$ & $P * *$ & $n$ & $M\left(P_{25}, P_{75}\right)$ & $\bar{Z}$ & $P^{* *}$ \\
\hline \multicolumn{9}{|l|}{ GSTT1 } \\
\hline+ & 99 & $1.50(1.06,2.69)$ & 0.653 & 0.514 & 67 & $0.94(0.74,1.27)$ & 1.100 & 0.271 \\
\hline- & 81 & $1.50(1.19,2.43)$ & & & 48 & $1.04(0.77,1.45)$ & & \\
\hline \multicolumn{9}{|l|}{ GSTM1 } \\
\hline+ & 85 & $1.42(1.07,2.14)$ & 1.266 & 0.205 & 51 & $0.91(0.71,1.08)$ & 2.911 & 0.004 \\
\hline- & 95 & $1.60(1.16,2.91)$ & & & 64 & $1.12(0.77,1.47)$ & & \\
\hline \multicolumn{9}{|l|}{ GSTP1 rs 1695} \\
\hline $\mathrm{GG}+\mathrm{AG}$ & 54 & $1.73(1.30,3.16)$ & 2.262 & 0.024 & 44 & $0.94(0.78,1.34)$ & 0.253 & 0.800 \\
\hline $\mathrm{AA}$ & 126 & $1.46(1.06,2.24)$ & & & 71 & $0.94(0.75,1.32)$ & & \\
\hline \multicolumn{9}{|c|}{ CYP2E1rs6413432 } \\
\hline TT & 97 & $1.50(1.15,2.37)$ & Ref* & & 68 & $0.94(0.74,1.33)$ & Ref* & \\
\hline AT & 72 & $1.50(1.02,2.97)$ & 0.286 & 0.775 & 42 & $1.04(0.79,1.29)$ & 0.381 & 0.704 \\
\hline AA & 11 & $1.64(1.05,3.17)$ & 0.276 & 0.782 & 5 & $0.71(0.65,1.21)$ & 1.157 & 0.247 \\
\hline$\chi^{2}\left(P^{*}\right)$ & & $0.200(0.905)$ & & & & $1.668(0.434)$ & & \\
\hline \multicolumn{9}{|c|}{ CYP2E1rs3813867 } \\
\hline GG & 106 & $1.50(1.13,2.46)$ & Ref* & & 60 & $0.95(0.73,1.35)$ & Ref* & \\
\hline $\mathrm{CG}$ & 65 & $1.50(1.03,2.70)$ & 0.395 & 0.693 & 50 & $1.04(0.79,1.30)$ & 0.381 & 0.703 \\
\hline $\mathrm{CC}$ & 9 & $1.64(1.11,4.16)$ & 0.698 & 0.485 & 5 & $0.71(0.65,1.00)$ & 1.613 & 0.107 \\
\hline$\chi^{2}\left(P^{*}\right)$ & & $0.760(0.684)$ & & & & $3.083(0.214)$ & & \\
\hline \multicolumn{9}{|l|}{ PON2 rs 12026} \\
\hline $\mathrm{CC}$ & 125 & $1.48(1.08,2.53)$ & 1.099 & 0.272 & 62 & $0.94(0.74,1.34)$ & 0.443 & 0.658 \\
\hline $\mathrm{CG}+\mathrm{GG}$ & 55 & $1.66(1.20,2.74)$ & & & 53 & $0.95(0.76,1.32)$ & & \\
\hline
\end{tabular}

$P^{*}$ : To compare telomere lengths among genotypes using a rank test of $\mathrm{k}$ independent samples; $P^{* *}$ : The comparing results between the two groups, the Bonferroni method was adopted; * Ref: The reference group of comparing different genotypes.

telomere length of GG+AG genotypes for GSTP1 rs1695 polymorphism locus was statistically significant longer than that of the AA genotype in the exposure group $(\mathrm{Z}=$ $2.262, P=0.024)$, and the genotypes of other loci had no statistically significant differences $(P>0.05)$.

\section{The effects of risk factors on relative telomere length in omethoate-exposed workers}

The influencing factors were screened using multiple linear regression. The data of telomere length was logarithmically transformed to meet the conditions of multiple linear regression analysis because of its abnormal distribution. Ln (natural logarithm) was established (Telomere length) as the dependent variable, and the independent variables were dummy variables, and screen the independent variables using a stepwise method. The variables kept in the models included group $(b=0.524, P<$ $0.001)$, GSTM1 gene polymorphism $(b=-0,136, P=0.029)$. No found that gender, alcohol, smoking, age, working duration and GSTT1, GSTP1 rs1695, CYP2E1 rs6413432, CYP2E1 rs3813867, PON2 rs12026 genetic polymorphism were included in the model. Table 4 showed the results.

\section{DISCUSSION}

Telomeres are specialized DNA-protein structures at the ends of the linear chromosomes. Their role is to protect the integrity and stability of the chromosome [12, 18]. At present, the results in a large number of studies showed that telomeres and telomerase abnormalities were related to tumor formation; however, Professor Carol Greider has proposed that telomerase was not able to explain why telomeres have a certain length and how to extend the length of telomeres, and longer telomeres were often directly related to cancer [19].

At present, the research results were different in the changes of telomere length caused by poisons; many studies suggested that different toxicants could cause telomere shortening [20, 21]. However, some studies found that toxicants could extend telomere length [22, 23]. Elongated telomere length has been observed as an early response after low-dose chemical carcinogens in vitro and animal experiments, suggesting low-dose carcinogenic chemical exposure may function as a tumor promoter at the early stage of human carcinogenesis [22]. This crosssectional study also found that relative telomere lengths 
Table 4: Independent variables of entering the regression model

\begin{tabular}{lccccc}
\hline \multicolumn{1}{c}{ Variables } & $\begin{array}{c}\text { Unstandardized } \\
\text { Coefficient }\end{array}$ & Standard Error & $\begin{array}{c}\text { Standardized } \\
\text { Coefficient }\end{array}$ & $\boldsymbol{t}$ & 1.083 \\
\hline Constant term & 0.061 & 0.057 & 0.280 \\
Exposure category & 0.524 & 0.063 & 0.433 & 8.266 & $<0.001$ \\
GSTM1 & -0.136 & 0.062 & -0.115 & -2.199 & 0.029 \\
\hline
\end{tabular}

in the exposure population were significantly longer than that of the control $(Z=-7.910, P<0.001)$; And we found that the relative telomere length decreased with the extension of working duration in the exposure group. The assessment of the occupational exposure level was lower than occupational exposure limits prescribed by China in each type of work, indicating that low-dose omethoate exposure caused the extension of telomere length.

We also analyzed the effects of gender, age, smoking and drinking on telomere length. Considering the influence of age on telomere length, we analyzed the correlation between age and telomere length using the Spearman rank correlation, we found that there was no correlation in the exposure or control group, respectively $\left(r_{s}=0.049, P=\right.$ $\left.0.517 ; r_{s}=0.116, P=0.218\right)$. Univariate analysis have no found that gender, age, smoking, drinking and working duration had effect on the relative telomere length in the exposure or control group $(P>0.05)$; Multivariate analysis showed that they also had no effect on telomere length $(P>0.05)$, which was consistent with that of univariate analysis.

Genetic injury is the chronic toxic effect of organophosphorus pesticide on the exposure- crowd. The studies in this area are mainly involving in the comet assay and micronucleus test [24-27]. However, genetic injury cannot occur in all individuals who have the same contact condition, suggesting that omethoate-exposure population have different genetic susceptibility. Therefore, this study analyzed the impact of GSTM1, GSTT1, GSTP1, CYP2E1 and PON2 genetic polymorphisms on telomere length. The analysis found that the relative telomere length of the GSTM1 polymorphism deletion genotype was significantly longer than that of the non-deletion genotype in the control group $(P=0.004)$, and the relative telomere length of GG+AG genotypes for GSTP1 rs1695 polymorphism locus was longer than that of AA genotype in the exposure group. The difference was statistically significant $(P$ $=0.024$ ). Liu et al. [28] indicated that individuals with susceptible metabolic GSTP1 genotypes could experience an increased risk of DNA damage elicited by pesticide exposure, which is similar to the results of this study. Singh et al. [13] also concluded that the GSTM1 null genotype could increase tail moment of the comet assay in workers occupationally exposed to OPs. Gorukmez O et al. [29] found that there was a significant correlation between colorectal cancer and the GSTP1 Ile-Ile genotype when the relationship between GSTT1, GSTM1 and GSTP1 genetic polymorphisms and colorectal cancer was explored. Wong et al [15] researched the relationship between XRCC1, CYP2E1 and ALDH2 genetic polymorphisms and sister chromatid exchange (SCE) frequency and found that CYP2E1 genetic polymorphism was significantly associated with an increased SCE frequency. A large number of studies have shown that variants of rs12026 within the PON2 gene were associated with cardiovascular disease, cerebrovascular disease, diabetes and other diseases [16, 30, 31]. Paraoxonase2 (PON2) is a member of the paraoxonase gene family which can protect cells from oxidative stress and thus protect chromosomes from damage. However, the results of this study showed that CYP2E1rs6413432, CYP2E1rs3813867, PON2rs12026 genetic polymorphisms had no effect on telomere length in either group, suggesting that the individual's susceptibility is different to different poisons. Multivariate analysis showed that pesticide exposure $(b=0.524, P<0.001)$ and GSTM1 $(b=-0.136, P=$ $0.029)$ were the influencing factors of telomere length, which was consistent with univariate analysis. Therefore, the statistically significant associations between omethoate and telomere length themselves imply the importance of environmental factors such as omethoate and genetic susceptibility in determining telomere length compared with conventional risk factors.

\section{MATERIALS AND METHODS}

\section{Study population}

180 long-term omethoate-exposed workers for longer than 8 years were recruited, and 115 healthy controls were recruited without a history of exposure to OPs or other toxicants, they all lived in the same city. Written informed consent was obtained from each subject, we collected occupational history, basic situation and biological samples for future studies.

\section{Research methods}

\section{The detection of relative telomere length}

Genomic DNA was isolated from peripheral blood lymphocytes, real-time PCR method was applied to determine the relative telomere length, and each sample was run in 3 parallel samples [32].

The PCR was carried out in a volume of $20 \mu \mathrm{l}$ containing 50 ng of genomic DNA, $2 \times$ AceQ qPCR SYBR 
Green Master Mix $10 \mu \mathrm{l}$ (Vazyme Biotech co., ltd) and 200 $\mathrm{nM}$ each primer (Beijing Invitrogen Corporation). PCR reaction conditions of telomere were as follows: Step1: $15 \mathrm{~min}$ at $95^{\circ} \mathrm{C}$; Step2: 2 cycles of $15 \mathrm{~s}$ at $94^{\circ} \mathrm{C}, 15 \mathrm{~s}$ at $49^{\circ} \mathrm{C}$; and, Step3: 32 cycles of $15 \mathrm{~s}$ at $94^{\circ} \mathrm{C}, 10 \mathrm{~s}$ at $62^{\circ} \mathrm{C}$, $15 \mathrm{~s}$ at $74^{\circ} \mathrm{C}$. PCR reaction conditions of reference were as follows: Step 1: $15 \mathrm{~min}$ at $95^{\circ} \mathrm{C}$; Step2: 2 cycles of 15 $\mathrm{s}$ at $94^{\circ} \mathrm{C}, 15 \mathrm{~s}$ at $49^{\circ} \mathrm{C}$; and, Step3: 32 cycles of $15 \mathrm{~s}$ at $94^{\circ} \mathrm{C}, 10 \mathrm{~s}$ at $62^{\circ} \mathrm{C}, 15 \mathrm{~s}$ at $88^{\circ} \mathrm{C}$. Data collection was directly completed in the software of ABI 7500 Fast realtime quantitative PCR instrument, and the formula of $2^{-\Delta \Delta \mathrm{Ct}}$ $\left(\Delta \mathrm{Ct}=\mathrm{Ct}_{\text {Telomere }}-\mathrm{Ct}_{\text {Reference, }} \Delta \Delta \mathrm{Ct}=\Delta \mathrm{Ct}-\Delta \mathrm{Ct}_{\text {average normal controls }}\right)$ was used to calculate the relative telomere length.

\section{The detection of genetic polymorphisms}

Six polymorphic loci of GSTT1(+/-), GSTM1 $(+/-)$, GSTP1 rs1695,CYP2E1 rs6413432, CYP2E1 rs3813867 and PON2 rs12026 from five genes were detected using genomic DNA isolated from peripheral blood lymphocytes. Multiplex PCR were used to detect the deletion in GSTT1 and GSTM1; PCR-RFLP method was used to detect other loci for genotyping; primer sequences and restriction endonucleases were described previously [30, 33]. The PCR and enzyme reaction conditions referred to the published paper in task group [34]; just in the experimental process of PCR, we should select a different annealing temperature depending on the Tm value and pre-experimental results.

\section{Statistical analysis}

SPSS21.0 software was used to analyze the data. Methods of representation and examination were based on the distribution of quantitative data. The Spearman rank correlation was used to analyze the correlation between age and telomere length. Using a rank sum test analyzed the effects of genetic polymorphisms on the relative telomere length and the Bonferroni method was used to do the comparisons between the two groups. Multiple linear regression was performed to analyze the influencing factors of telomere length. All statistical tests were twosided, and the criterion for statistical significance was set at $P<0.05$ for all tests.

\section{CONCLUSIONS}

In conclusion, the relative telomere length became longer in peripheral blood leukocytes DNA for the omethoate-exposure workers. The length was associated with pesticide exposure and GSTM1 gene polymorphism. The study found that the relative telomere length of the GSTM1 polymorphism deletion genotype was significantly longer than that of the non - deletion genotype, and the relative telomere length of $\mathrm{GG}+\mathrm{AG}$ genotype for GSTP1rs1695 polymorphism locus was longer than that of the AA genotype for the first time. The research results provide strong evidence for the mechanism research of telomere damage induced by poison and for screening effective susceptible biomarkers.

\section{ACKNOWLEDGMENTS AND FUNDING}

The authors expressed their gratitude to all the individuals who volunteered to participate in this study. We are also thankful for the support from the Programs for Science and Technology Development of Zhengzhou (131PPTGG376) and the Outstanding Youth Grant of Zhengzhou University (1521329035).

\section{CONFLICTS OF INTEREST}

None.

\section{REFERENCES}

1. Bird SB, Krajacic P, Sawamoto K, Bunya N, Loro E, Khurana TS. Pharmacotherapy to protect the neuromuscular junction after acute organophosphorus pesticide poisoning. Ann N Y Acad Sci. 2016; 1374:86-93.

2. Lionetto MG, Caricato R, Calisi A, Giordano ME, Schettino T. Acetylcholinesterase as a biomarker in environmental and occupational medicine: new insights and future perspectives. Biomed Res Int. 2013; 2013:321213.

3. Weichenthal S, Moase C, Chan P. A review of pesticide exposure and cancer incidence in the Agricultural Health Study cohort. Environ Health Perspect. 2010; 118:1117-1125.

4. Sanchez-Pena LC, Reyes BE, Lopez-Carrillo L, Recio R, Moran-Martinez J, Cebrian ME, Quintanilla-Vega B. Organophosphorous pesticide exposure alters sperm chromatin structure in Mexican agricultural workers. Toxicol Appl Pharmacol. 2004; 196:108-113.

5. Jamal GA, Hansen S, Pilkington A, Buchanan D, Gillham RA, Abdel-Azis M, Julu PO, Al-Rawas SF, Hurley F, Ballantyne JP. A clinical neurological, neurophysiological, and neuropsychological study of sheep farmers and dippers exposed to organophosphate pesticides. Occup Environ Med. 2002; 59:434-441.

6. Akyil D, Konuk M. Detection of genotoxicity and mutagenicity of chlorthiophos using micronucleus, chromosome aberration, sister chromatid exchange, and Ames tests. Environ Toxicol. 2015; 30:937-945.

7. Costa C, Silva S, Neves J, Coelho P, Costa S, Laffon B, Snawder J, Teixeira JP. Micronucleus frequencies in lymphocytes and reticulocytes in a pesticide-exposed population in Portugal. J Toxicol Environ Health A. 2011; 74:960-970.

8. How V, Hashim Z, Ismail P, Omar D, Said SM, Tamrin SB. Characterization of risk factors for DNA damage among paddy farm worker exposed to mixtures of organophosphates. Arch Environ Occup Health. 2015; 70:102-109. 
9. Kapka-Skrzypczak L, Cyranka M, Skrzypczak M, Kruszewski M. Biomonitoring and biomarkers of organophosphate pesticides exposure - state of the art. Ann Agric Environ Med. 2011; 18:294-303.

10. Undeger U, Basaran N. Assessment of DNA damage in workers occupationally exposed to pesticide mixtures by the alkaline comet assay. Arch Toxicol. 2002; 76:430-436.

11. Undeger U, Basaran N. Effects of pesticides on human peripheral lymphocytes in vitro: induction of DNA damage. Arch Toxicol. 2005; 79:169-176.

12. O'Sullivan RJ, Karlseder J. Telomeres: protecting chromosomes against genome instability. Nat Rev Mol Cell Biol. 2010; 11:171-181.

13. Singh S, Kumar V, Singh P, Banerjee BD, Rautela RS, Grover SS, Rawat DS, Pasha ST, Jain SK, Rai A. Influence of CYP2C9, GSTM1, GSTT1 and NAT2 genetic polymorphisms on DNA damage in workers occupationally exposed to organophosphate pesticides. Mutat Res. 2012; 741:101-108.

14. Wong RH, Chang SY, Ho SW, Huang PL, Liu YJ, Chen YC, Yeh YH, Lee HS. Polymorphisms in metabolic GSTP1 and DNA-repair XRCC1 genes with an increased risk of DNA damage in pesticide-exposed fruit growers. Mutat Res. 2008; 654:168-175.

15. Wong RH, Wang JD, Hsieh LL, Cheng TJ. XRCC1, CYP2E1 and ALDH2 genetic polymorphisms and sister chromatid exchange frequency alterations amongst vinyl chloride monomer-exposed polyvinyl chloride workers. Arch Toxicol. 2003; 77:433-440.

16. Li S, Fang K, Wang W, Hu Y, Chen D. Gene-environment interaction among GSTT1, PON2 polymorphisms and organic solvents on gestational age in a Chinese women cohort. J Assist Reprod Genet. 2014; 31:881-888.

17. Wu X, Zhao H, Amos CI, Shete S, Makan N, Hong WK, Kadlubar FF, Spitz MR. p53 Genotypes and Haplotypes Associated With Lung Cancer Susceptibility and Ethnicity. J Natl Cancer Inst. 2002; 94:681-690.

18. Wulaningsih W, Watkins J, Matsuguchi T, Hardy R. Investigating the associations between adiposity, life course overweight trajectories, and telomere length. Aging (Albany NY). 2016; 8:2689-2701. http://doi.org/10.18632/aging.101036.

19. Lee SS, Bohrson C, Pike AM, Wheelan SJ, Greider CW. ATM Kinase Is Required for Telomere Elongation in Mouse and Human Cells. Cell Rep. 2015; 13:1623-1632.

20. Wu Y, Liu Y, Ni N, Bao B, Zhang C, Lu L. High lead exposure is associated with telomere length shortening in Chinese battery manufacturing plant workers. Occup Environ Med. 2012; 69:557-563.

21. Li H, Jonsson BA, Lindh $\mathrm{CH}$, Albin $\mathrm{M}$, Broberg $\mathrm{K}$. $\mathrm{N}$-nitrosamines are associated with shorter telomere length. Scand J Work Environ Health. 2011; 37:316-324.

22. Shin JY, Choi YY, Jeon HS, Hwang JH, Kim SA, Kang JH, Chang YS, Jacobs DR, Jr., Park JY, Lee DH. Low-dose persistent organic pollutants increased telomere length in peripheral leukocytes of healthy Koreans. Mutagenesis. 2010; 25:511-516.
23. Dioni L, Hoxha M, Nordio F, Bonzini M, Tarantini L, Albetti B, Savarese A, Schwartz J, Bertazzi PA, Apostoli P, Hou L, Baccarelli A. Effects of short-term exposure to inhalable particulate matter on telomere length, telomerase expression, and telomerase methylation in steel workers. Environ Health Perspect. 2011; 119:622-627.

24. Benitez-Trinidad AB, Herrera-Moreno JF, VazquezEstrada G, Verdin-Betancourt FA, Sordo M, OstroskyWegman P, Bernal-Hernandez YY, Medina-Diaz IM, Barron-Vivanco BS, Robledo-Marenco ML, Salazar AM, Rojas-Garcia AE. Cytostatic and genotoxic effect of temephos in human lymphocytes and HepG2 cells. Toxicol In Vitro. 2015; 29:779-786.

25. Timoroglu I, Yuzbasioglu D, Unal F, Yilmaz S, Aksoy H, Celik M. Assessment of the genotoxic effects of organophosphorus insecticides phorate and trichlorfon in human lymphocytes. Environ Toxicol. 2014; 29:577-587.

26. Jonnalagadda PR, Jahan P, Venkatasubramanian S, Khan IA, Prasad A, Reddy KA, Rao MV, Venkaiah K, Hasan Q. Genotoxicity in agricultural farmers from Guntur district of South India-A case study. Hum Exp Toxicol. 2012; 31:741-747.

27. Hreljac I, Filipic M. Organophosphorus pesticides enhance the genotoxicity of benzo(a)pyrene by modulating its metabolism. Mutat Res. 2009; 671:84-92.

28. Liu YJ, Huang PL, Chang YF, Chen YH, Chiou YH, Xu ZL, Wong RH. GSTP1 genetic polymorphism is associated with a higher risk of DNA damage in pesticide-exposed fruit growers. Cancer Epidemiol Biomarkers Prev. 2006; 15:659-666.

29. Gorukmez O, Yakut T, Sag SO, Topak A, Sahinturk S, Kanat O. Glutathione S-transferase T1, M1 and P1 Genetic Polymorphisms and Susceptibility to Colorectal Cancer in Turkey. Asian Pac J Cancer Prev. 2016; 17:3855-3859.

30. Duan X, Yang Y, Wang T, Feng X, Yao WU, Yan Z, Wang W. An improved polymerase chain reaction-restriction fragment length polymorphism assay for the detection of a PON2 gene polymorphism. Biomed Rep. 2016; 5:133-135.

31. Li X, Cao J, Wang J, Song H, Ji G, Dong Q, Wei C, Cao Y, Wang B, Zhu B, Xiao H. PON2 and ATP2B2 gene polymorphisms with noise-induced hearing loss. J Thorac Dis. 2016; 8:430-438.

32. Cawthon RM. Telomere length measurement by a novel monochrome multiplex quantitative PCR method. Nucleic Acids Res. 2009; 37:e21.

33. Wang W, Qiu YL, Ji F, Liu J, Wu F, Miao WB, Li Y, BrandtRauf PW, Xia ZL. Genetic polymorphisms in metabolizing enzymes and susceptibility of chromosomal damage induced by vinyl chloride monomer in a Chinese worker population. J Occup Environ Med. 2010; 52:163-168.

34. Duan X, Yang Y, Wang S, Feng X, Wang T, Wang P, Liu S, Li L, Yao W, Cui L, Wang W. Changes in the expression of genes involved in cell cycle regulation and the relative telomere length in the process of canceration induced by omethoate. Tumour Biol. 2017; 39:1010428317719782. 